\title{
Challenges and Opportunities Faced by Piano Basic Education in Universities
}

\section{Zhen Song}

Zhaoqing College Academy of Music, Zhaoqing 526061, Guangdong, China.

Abstract: The changes in society and the rapid development of the economy have enabled my country's education industry to innovate in the continuous development of the new era. College music majors have ushered in new opportunities in the wave of development, but at the same time, they also have many problems. How to ensure the better progress of education in the process of changing the times has become a major problem for many teachers. This article starts with the main factors restricting the development of piano basic classrooms in colleges and universities, looking for specific ways to promote its better development, hoping to help other music teachers to learn from.

Keywords: Educational Opportunities; Educational Reform; Higher Education; Piano Classroom

The reform of the higher education system has achieved better development in the context of changes in the times, so many schools pay more and more attention to the effectiveness of teaching basic education. As a compulsory classroom for music majors, piano education not only has a high learning ability, appreciation ability, speculative ability and comprehension ability of students, but also guarantees students a better development in the process of ensuring their musical literacy. This requires teachers to be able to find the specific reasons that affect the orderly development of teaching activities after careful analysis of the actual situation of the class students in the piano basic classroom, and find solutions from the teaching practice. This not only enables students to stimulate learning enthusiasm, teachers also establish high-quality basic education classrooms in the process of changing old teaching methods, so that students can become high in meeting the social requirements in the process of learning knowledge and professional playing skills Accomplish piano talents.

\section{The main factors restricting the development of piano basic classroom in colleges and universities}

\subsection{Student learning differences are obvious}

Because colleges and universities have a wide range of students when recruiting students, and students' own knowledge reserves, speculative awareness, learning ability, and piano basic levels are quite different, teachers in classroom teaching activities, if there is no actual student Careful analysis of the learning situation, then in the course of teaching, it is easy to appear that it is difficult to mobilize students' learning initiative, which will seriously affect the smooth development of normal piano basic teaching. In addition, although the thinking consciousness of college students has gradually developed, due to the obvious differences in students' living environment, psychological factors, personality characteristics and other reasons, when teachers are teaching, how can they not pay attention to the status of the students' individual development, then It is easy to affect students' enthusiasm for learning, resulting in a serious decline in their learning efficiency.

\subsection{The teaching method is too simple}

Many teachers do not pay attention to the importance of innovating their own teaching methods when teaching basic piano lessons. When teaching students' performance skills, they are usually connected with the works of musicians that are

Copyright(C) 2020 Zhen Song

doi: 10.18686/ahe.v4i10.2913

This is an open-access article distributed under the terms of the Creative Commons Attribution Non-Commercial License (http://creativecommons. org/licenses/by-nc/4.0/), which permits unrestricted non-commercial use, distribution, and reproduction in any medium, provided the original work is properly cited. 
familiar to students. Although the artistic value of these famous repertoires is excellent, in this over-single teaching method, it is difficult for students to mobilize the initiative to participate in piano knowledge learning, and it is difficult to coordinate the content of the lectures with their learning. On the quality of students' learning. Students in a single learning environment for a long time, not only their own ability to improve their thinking ability will be limited, but also difficult to exert their own subjective initiative, resulting in deteriorating learning efficiency, teachers need to focus on solving.

\section{Opportunities for the smooth development of piano basic classes in colleges and universities}

\subsection{Respect students' learning level}

In order to ensure the smooth progress of the basic education of music and piano, teachers need to make close contact with students before class, after fully understanding the learning level, thinking characteristics, thinking ability and learning needs of class students. Establish a piano classroom environment more in line with its development requirements. This not only allows students to fully experience the fun of learning piano knowledge, but also in the process of training their playing skills and artistic literacy, so that students can grow into excellent piano music talents. In addition, in view of the uneven knowledge reserves of students, teachers need to use Internet resources to collect piano basic teaching resources that match the students' learning needs, upload them to the campus network platform, and require students to use their spare time after class. Study materials to learn. This can not only effectively enrich the students' knowledge reserves, but also cultivate their good habits of active learning, and then lay the foundation for the smooth development of piano basic education classes.

\subsection{Pay attention to the innovation of teaching methods}

The piano basic classroom is the basis for ensuring students' better knowledge learning in the future. Therefore, when teaching, teachers need to focus on teaching the basic level of students in order to exercise their performance ability, appreciation ability and artistic perception ability. To enable students to achieve comprehensive development. Therefore, teachers need to break through the constraints of the old teaching concept, through the analysis of students' learning needs, plan to choose different teaching methods, so that students can meet the requirements of their own piano teaching to ensure the rapid rise of learning efficiency.

For example, in order to strengthen students' basic piano performance skills, teachers can use the cooperative learning model to carry out teaching activities. The teacher divides the classmates into different groups according to the basic learning situation of the students, so that the students with higher piano basic level can help the weaker students to complete the learning of knowledge during the learning activities. At the same time, teachers also need to develop in a practical way, and arrange different performance themes for each group. In this way, students can learn knowledge more actively through the collection of performance materials and rehearsal of performance forms in mutual help before class. Teachers need to reach out to students and give them some guidance on their learning content and performance methods, so that students can better complete the learning of piano basics under the encouragement of teachers, and can also cooperate with team members To ensure rapid progress in learning quality.

\section{Conclusion}

In a word, in order to ensure the smooth progress of the piano basic education, teachers should proceed from the actual situation of students on the one hand when teaching, so that they can stimulate the initiative of participating in the piano classroom under the guidance of teachers, on the other hand, teachers It is necessary to break the bad factors that hinder the smooth development of classroom teaching activities, and establish a piano classroom that can enable students to improve professional skills and musical literacy. Therefore, teachers should pay close attention to the development of the times and actively find the main way to promote the smooth development of education, so that they can grow into music talents who meet the requirements of national development in the process of meeting the development requirements of education reform.

\section{References}

1. Liu HF, Yu YD. Discussion on the thinking of piano teaching reform in the new period-Comment on "research on piano teaching reform and practice paths in colleges and universities". Journal of Chinese Education 2020; (05): 109.

2. Lu TT. Development and reform of university piano course teaching in the information age —Comment on "research and reform of piano teaching in colleges and universities". Higher Education Exploration 2020; (04): 144.

3. Xiao Y. The importance and difficulties of Anna's Notebook in basic piano teaching in private colleges and universities. Art Review 2020; (06): 109-110. 